\title{
Pengaruh Variasi Putaran Terhadap Nilai Kekerasan, Kekuatan Tarik dan Struktur Mikro Alumunium Matrix Composite (AMC) Hasil Stir Casting Dengan Paduan Mg dan SiC yang Berlebih
}

\author{
Iman Saefuloh', Agus Pramono², Muhamad Latief ${ }^{3}$, Hesti Istiqlaliyah ${ }^{4}$ \\ 1),3) Teknik Mesin, Universitas Sultan Ageng Tirtayasa, Banten, Indonesia \\ 2) Teknik Metalurgi, Universitas Sultan Ageng Tirtayasa, Banten, Indonesia \\ 4) Teknik Mesin, Universitas Nusantara PGRI Kediri, Kediri, Jawa Timur, Indonesia \\ E-mail : ${ }^{1}$ iman.saefuloh@ untirta.ac.id, ${ }^{4}$ hestiisti@unpkediri.ac.id
}

\begin{abstract}
Abstrak
Penelitian ini bertujuan untuk menganalisa pengaruh perubahan parameter proses terhadap kekerasan, kuat tarik, dan struktur mikro alumunium matrix composite (AMC) dengan komposisi $\mathrm{Al5 \%} \mathrm{Cu}-12 \% \mathrm{Mg}-15 \% \mathrm{SiC}$ setelah melalui proses perubahan varian kecepatan putar, dimana kecepatan stir casting adalah 1000, 2000 dan $3000 \mathrm{rpm}$. Dari hasil pengujian didapatkan nilai kekerasan tertinggi dicapai pada kecepatan putar $3000 \mathrm{rpm}$ yaitu 105,6 BH dan nilai kuat tarik tertinggi dicapai pada putaran $2000 \mathrm{rpm}$ yaitu $72,7 \mathrm{~N} / \mathrm{mm} 2$, dan hasil pengamatan struktur mikro menunjukan penguat unsur $\mathrm{C}, \mathrm{Mg}$ dan $\mathrm{SiC}$ lebih merata pada kecepatan putar 2000 dan 3000 rpm. Dari perbedaan perubahan nilai kekerasan, kuat tarik dan struktur mikro tersebut membuktikan bahwa terdapat pengaruh parameter proses perubahan kecepatan putar stir casting terhadap nilai kekerasan, kuat tarik dan struktur mikro AMC.
\end{abstract}

Kata kunci: Alumunium matrix composite, variasi putaran, stir casting.

\begin{abstract}
This study aims to analyze the effect of changing process parameters on hardness, tensile strength, and micro structure of aluminum matrix composite (AMC) with the composition of $\mathrm{Al5 \%} \mathrm{Cu}-12 \% \mathrm{Mg}-15 \% \mathrm{SiC}$ after going through the process of changing the rotational speed variant, where the stir casting speed is 1000, 2000 and $3000 \mathrm{rpm}$. From the test results obtained the highest hardness value is achieved at a rotational speed of $3000 \mathrm{rpm}$ which is $105.6 \mathrm{BH}$ and the highest tensile strength value is achieved at 2000 rpm rotation which is $72.7 \mathrm{~N} / \mathrm{mm} 2$, and the results of microstructure observations show the reinforcement of elements $\mathrm{C}, \mathrm{Mg}$ and $\mathrm{SiC}$ more evenly distributed at 2000 and 3000 rpm rotational speeds. From the differences / changes in the value of hardness, tensile strength and microstructure, it is proved that there is an influence of the parameters of the change process of stir casting rotational speed on the value of hardness and tensile strength and microstructure of AMC.
\end{abstract}

Keywords: alumunium matrix composite, rotation variation, stir casting. 


\section{PENDAHULUAN}

Material alumunium matrix composite (AMC) semakin banyak dan sering digunakan untuk keperluan industri pesawat terbang, industri ottomotif, industri perkapalan dan industri pertahanan keamanan juga berbagai bahan konstruksi dan alat permesinan [1]. Sebagai contoh aplikasi AMC dalam kehidupan sehari-hari adalah bodi pesawat terbang, bodi ottomobil, mesin mobil. Hal dikarenakan AMC selain memiliki berat jenis (densitas) yang rendah/ringan juga memiliki kekuatan yang tinggi [2], selain itu AMC juga memiliki modulus elastisitas dan ketahanan terhadap aus yang tinggi [3].

Namun demikian seringkali AMC belum sepenuhnya menjawab kebutuhan yang menyeluruh tantangan didunia industri ataupun kebutuhan sehari-hari tersebut yang sesuai dengan kriteria yang diperlukan karena masih banyak terdapat kelemahankelemahannya. Oleh karena itu banyak dikembangkan jenis modifikasi AMC yang baru terutama dari kandungan paduan-paduan atau dari proses pembuatannya untuk menghasilkan sifat-sifat AMC baru dan lebih baik. Bahan paduan yang dapat ditambahkan sebagai penguat AMC untuk memperoleh sifat-sifat baru yang lebih baik contohnya antara lain $\mathrm{CU}, \mathrm{Mg}, \mathrm{SiC}$ dll. Untuk metode proses membuat AMC salah satunya adalah stir casting, stir casting adalah metode proses pengecoran dan pencetakan dengan memutar pengaduk yang diletakan didalam metal cair [4].

Parameter stir casting yang berpengaruh dan berperan penting dalam menentukan sifat fisik maupun mekanik material antara lain temperatur pengadukan, lama waktu pengadukan, salah satu parameter itu adalah perbedaan kecepatan putaran. Material composite merupakan pencampuran antara dua material yang berbeda secara mikroskopik dimana satu material berfungsi sebagai reinforced dan satunya lagi sebagai matrik sehingga menghasilkan material baru lebih kuat dari material sebelumnya [5] .

Dalam penggabungan material ada dua yaitu gabungan mikro (Composite) dan gabungan mikro (Paduan). Berdasarkan cara penguatannya composite penguatan structural. Dari beberapa jenis penguat partikel, composite penguat serat, composite penguat struktural. Dari beberapa jenis penguat ini, pengembangan composite fly ash yang dihasilkan dari pembakaran batubara [5-6]. 
Aluminium adalah jenis logam yang mempunyai ketahanan korosi, hantaran litstrik serta sifat yang baik lainnya sebagai sifat logam. Pada penelitian ini, aluminium yang akan digunakan sebagai bahan utama adalah aluminium bakas (scrap). Aluminium mempunyai manfaat dan kelebihan terdiri dari ringan ,tahan terhadap korosi,kuat,tahan terhadap suhu rendah,mudah di daur ulang ,perawatan yang mudah, non-spaking (tidak menimbulkan percikan api ketika material saling digosokan [7-9].
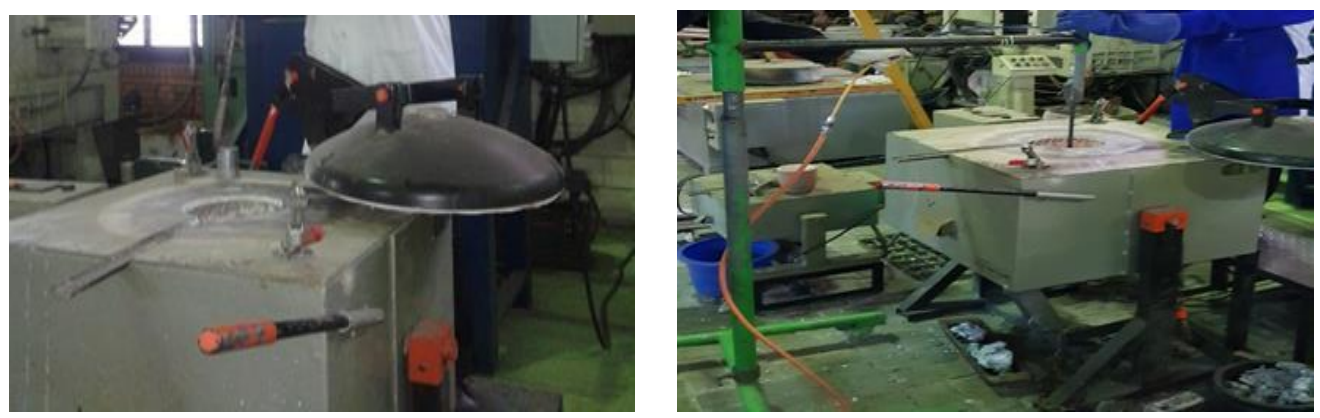

Gambar 1. Mesin stir casting

Proses Stir Casting adalah suatu metode pembuatan material composite dengan mencampurkan bahan material disaat material alam keadaan mencair, dimana pengadukannya secara mekanik. Tujuan utama dalam penelitian ini adalah untuk mengetahui pengaruh Tempratur Stir Casting yang digunakan Terhadap Sifat Mekanik Alumunium Matrix Composite (AMC). Pada penelitian yang sudah dilakukan, metode stir casting dapat meningkatkan sifat mekanis pada material Alumunium Matriks Composite (AMC) hal ini kuat Tarik dan kekerasan dengan memvariasikan temperatur, komposisi alloy AMC, waktu aging [10-12] .

Dalam penelitian ini penulis juga bermaksud untuk meningatkan sifat mekanis pada material Alumunium Matriks Composite (AMC) dengan metode tersebut. Dimana dalam penelitian ini penulis memvariasikan kecepatan putar pengadukan 1000 Rpm, 2000 Rpm dan 3000 Rpm.

\section{METODE PENELITIAN}

Pada proses pengecoran penelitian ini material yang digunakan Alumunium (Al), Tembaga (Cu), Silicon Carbida ( $\mathrm{SiC})$, dengan komposisi $\mathrm{Al}-5 \% \mathrm{Cu}-12 \% \mathrm{Mg}-$ $15 \%$ SiC dengan metode Stir Casting. proses pengecoran dan penuangan menggunakan teknik pengecoran gravitasi ketika memasukan Alumunium cair kedalam cetakan. 
Alumunium dicairkan didalam tungku/chamber pada temperatur $750^{\circ} \mathrm{C}$, kemudian dimasukan kedalam tungku stir casting. Bersamaan dengan proses pencairan/peleburan alumunium, SiC juga dipanaskan sampai temperatur $1000^{\circ} \mathrm{C}$ tujuan agar $\mathrm{SiC}$ mudah terlarut dan bercampur dengan alumunium, setelah temperatur mencapai temperatur $1000^{\circ} \mathrm{C}$ kemudian tahan beberapa menit, $\mathrm{SiC}$ yang sdh dipanaskan langsung dituangkan/dimasukan kedalam tungku/chamber stir casting dicampur dgn alumunium cair. Proses selanjutnya adalah mencampurkan $\mathrm{Mg}$ dan $\mathrm{Cu}$ kedalam stir casting sesuai dengan persentasi yang rencanakan yaitu $5 \% \mathrm{Cu}$ dan $12 \% \mathrm{Mg}$, mesin stir casting diputar dengan variasi putaran 1000, 2000, dan $3000 \mathrm{rpm}$ pada temperatur $600^{\circ} \mathrm{C}$ selama 1 Jam.

\section{HASIL DAN PEMBAHASAN}

\section{a. Hasil Pengujian kekerasan}

Proses pengujian kekerasan dapat diartikan sebagai kemampuan suatu bahan terhadap pembebanan dalam perubahan yang tetap, artinya ketika gaya tertentu diberikan pada suatu benda uji dan karena pengaruh pembebanan benda uji akan mengalami deformasi. Pengujian kekerasan menggunakan metode Brinell dengan beban 187,5 kgf dan diameter bola 2,5 mm dilakukan berdasarkan standar ASTM E-10.

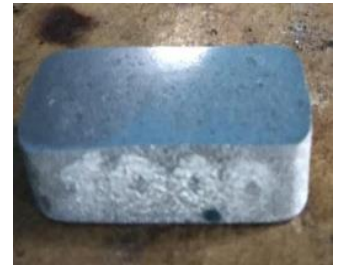

(a)

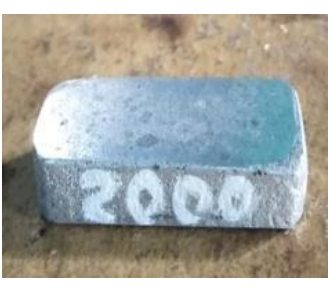

(b)

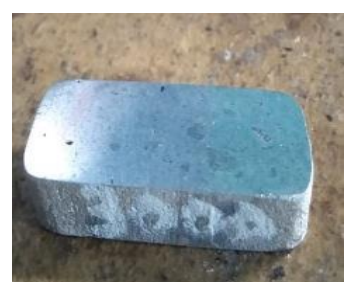

(c)

Gambar 3. Spesimen uji Kekerasan (a)1000 Rpm (b)2000 Rpm dan (c)3000 Rpm

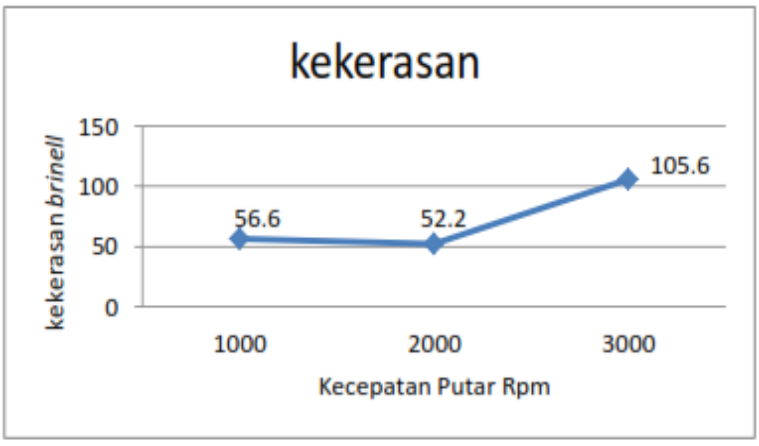

Gambar 4. Grafik hasil Pengujian nilai kekerasan terhadap kecepatan putar stir casting 
Melalui grafik diatas dapat dilihat bahwa penambahan kecepatan putar menaikan nilai kekerasan dari komposit. Pada kondisi kecepatan putar 1000 Rpm didapat bahwa nilai kekerasannya 56.6 HB dan mengalami penurunanan menjadi $52.2 \mathrm{HB}$ setelah mengalami kenaikan kecepatan putar menjadi 2000 Rpm (mengalami penurunan sebesar 8\%). Namun ketika ditambah kecepatan putar jadi $300 \mathrm{Rpm}$ nilai kekerasannya justru naik menjadi 105.6 HB (mengalami peningkatan sebesar 102\%). Hal ini dapat disebabkan melalui beberapa hal sesuai dengan literatur yang didapat penulis dan akan dijelaskan sebagai berikut.

Nilai kekerasan komposit aluminium yang lebih rendah dibandingkan monolithnya dipengaruhi oleh beberapa faktor, seperti pembasahan yang kurang baik pada material komposit, terbentuknya porositas pada matriks aluminium komposit, dan distribusi yang kurang merata dari penguat SiC. Pembasahan yang kurang baik antara matriks dan penguat dapat dibuktikan melalui pengamatan mikrostruktur. Antarmuka (fasa spinel $\mathrm{AlCuMg}$ ) yang terbentuk juga tidak optimum akibat suhu preheating penguat $\mathrm{SiC}$ yang tidak optimum, sehingga kemungkinan tidak terbentuk $\mathrm{SiO} 2$ pada permukaan serbuk penguat SiC. Dalam fabrikasi komposit, sebenarnya antarmuka memiliki peranan penting karena berfungsi sebagai penyalur gaya dari luar, menuju matriks, dan akhirnya penguat. Apabila antarmuka yang terbentuk kurang baik, maka kekuatan komposit juga rendah.

\section{b. Hasil Pengujian Tarik}

Pengujian tarik material aluminium matrix composit (AMC) menggunakan standar ASTM E8M-09 dengan kecepatan penarikan $10 \mathrm{~mm} / \mathrm{mnt}$ pada kondisi temperatur ruang $27^{\circ} \mathrm{C}$.
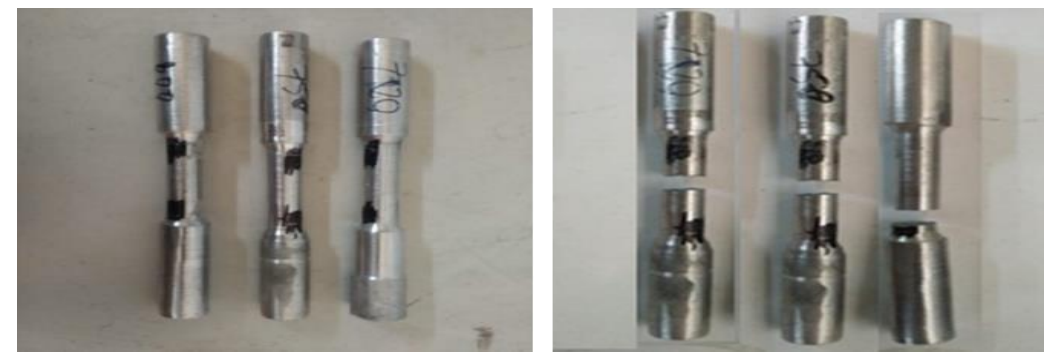

Gambar 5. Spesimen Uji tarik 


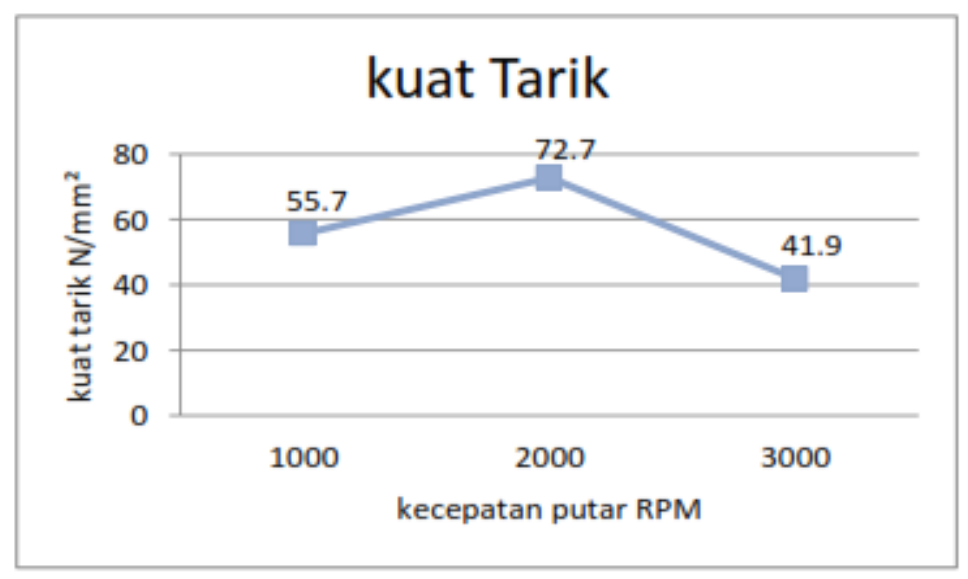

Gambar 6. Grafik Kuat Tarik

Dari gambar 6 dapat diketahui nilai kuat tarik hasil proses stir casting dengan kecepatan putar dari 1000 Rpm , 2000 Rpm dan 3000 Rpm didapatkan hasil uji tarik nilai tertinggi pada kecepatan 2000 Rpm dengan nilai kuat tarik sebesar 72.7 $\mathrm{N} / \mathrm{mm}^{2}$ dan untuk nilai beban tarik terendah didapat pada kecepatan $3000 \mathrm{Rpm}$ dengan nilai $41.9 \mathrm{~N} / \mathrm{mm}^{2}$. Pengaruh kecepatan putar pengadukan pada kekuatan tarik komposit $\mathrm{Al}-5 \% \mathrm{Cu}-12 \% \mathrm{Mg}-15 \% \mathrm{SiC}$ juga ditunjukkan pada garfik 4.2. Pada penelitian ini, ketika kecepatan putar pengadukan dinaikkan dari 1000 menjadi $2000 \mathrm{rpm}$, kekuatan tarik rata-rata komposit $\mathrm{Al}-5 \% \mathrm{Cu}-12 \% \mathrm{Mg}-15 \% \mathrm{SiC}$ naik, yaitu naik dari $55.7 \mathrm{~N} / \mathrm{mm}^{2}$ menjadi $72.7 \mathrm{~N} / \mathrm{mm}^{2}$ (mengalami kenaikanan sebesar 30\%). Namun terjadi penuruan menjadi $41.9 \mathrm{~N} / \mathrm{mm}^{2}$ ketika kecepatan putar pengadukan $3000 \mathrm{rpm}$ (mengalami penurunan sebesar 42\%). Berdasarkan garfik 4.2, ditunjukkan bahwa sinyal tertinggi terjadi pada variasi ke dua dengan $\mathrm{S} / \mathrm{N}$ ratio sebesar 72.7 $\mathrm{N} / \mathrm{mm}^{2}$, maka kecepatan putar optimum adalah $2000 \mathrm{rpm}$, Sebab semakin tinggi kecepatan putar menyebabkan delta temperatur liquidundercooling semakin tinggi dan tingginya kecepatan putar menyebabkan terjebaknya gas hidrogen semakin banyak sehingga nilai kekuatan tarik mengalami penurunan. Tidak terbentuknya precipitat $\mathrm{Mg} 2 \mathrm{Si}$ dengan baik sehingga nilai kekuatan tarik rendah. Faktor yang mempengaruhi terjadinya peningkatan nilai kekuatan tarik dan kekerasan bahan adalah terbentuknya precipitat $\mathrm{Mg} 2 \mathrm{Si}$ di dalam matrik $\mathrm{Al} \alpha$

\section{c. Pengamatan Struktur Mikro}

Terlihat dalam gambar 7, 8, dan 9 struktur mikro $\mathrm{Cu}$ sudah mengalami perubahan warna distribusi partikel $\mathrm{SiC}$ pada matrik komposit terlihat menyebabkan porositas berupa rongga halus pada permukaan partikel SiC seperti 
ditunjukkan pada gambar hasil struktur mikro. Porositas berupa rongga halus ini menjadikan ikatan antara permukaan partikel SiC dengan matrik aluminium menjadi berkurang dan menjadikan kekuatan tarik komposit menurun. Semakin bertambahnya kecepatan putar batas butir antara $\mathrm{SiC}$ dan matrik $\mathrm{AlCuMg}$ rapat mulai dari variasi kecepatan 1000 Rpm, 2000 Rpm. 3000 Rpm.

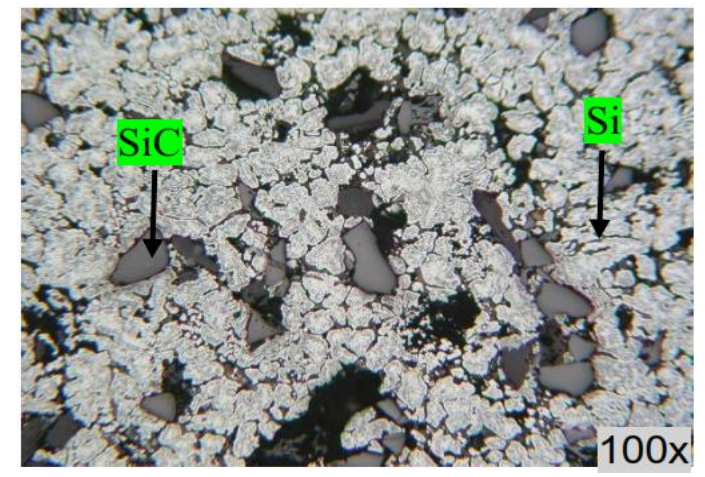

(a)

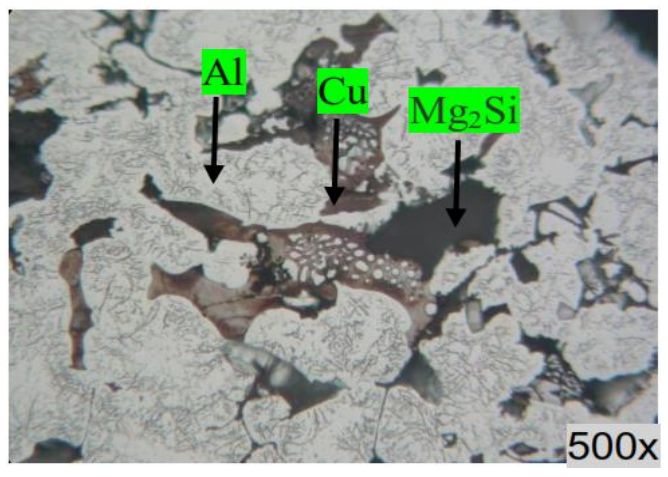

(b)

Gambar 7. Struktur mikro sampel kode 1000 material Al-SiC berupa aluminium (putih), $\mathrm{SiC}$ (abu abu butir besar), Silisium (sebagai batas butir dan telah menyebar pada butiran) dan $\mathrm{Cu}$ yang sudah mengalami perubahan warna. (a) perbesaran 100x (b) perbesaran 500x. Etsa: Dix's keller reagent

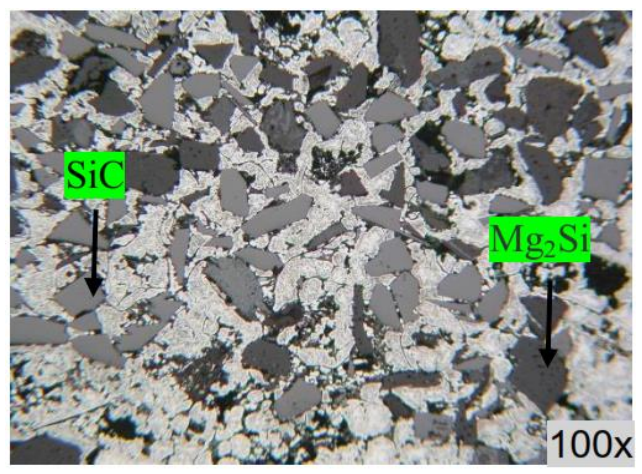

(a)

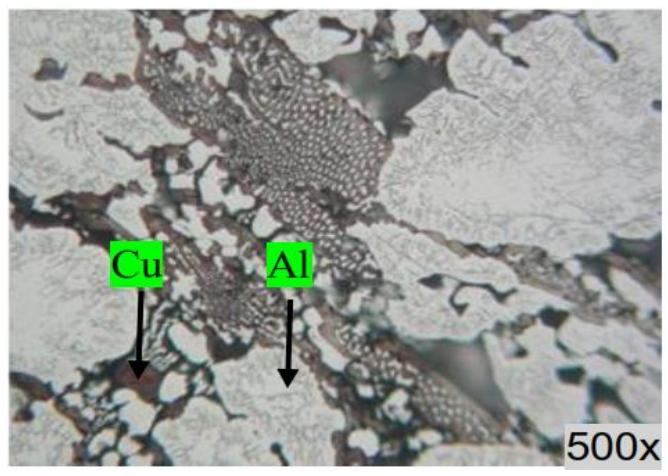

(b)

Gambar 8 Struktur mikro sampel kode 2000 material Al-SiC berupa aluminium (putih), SiC (abu abu butir besar), Silisium (sebagai batas butir dan telah menyebar pada butiran) dan $\mathrm{Cu}$ yang sudah mengalami perubahan warna (a) perbesaran 100x dan (b) perbesaran 500x. Etsa: Dix's keller reagent 

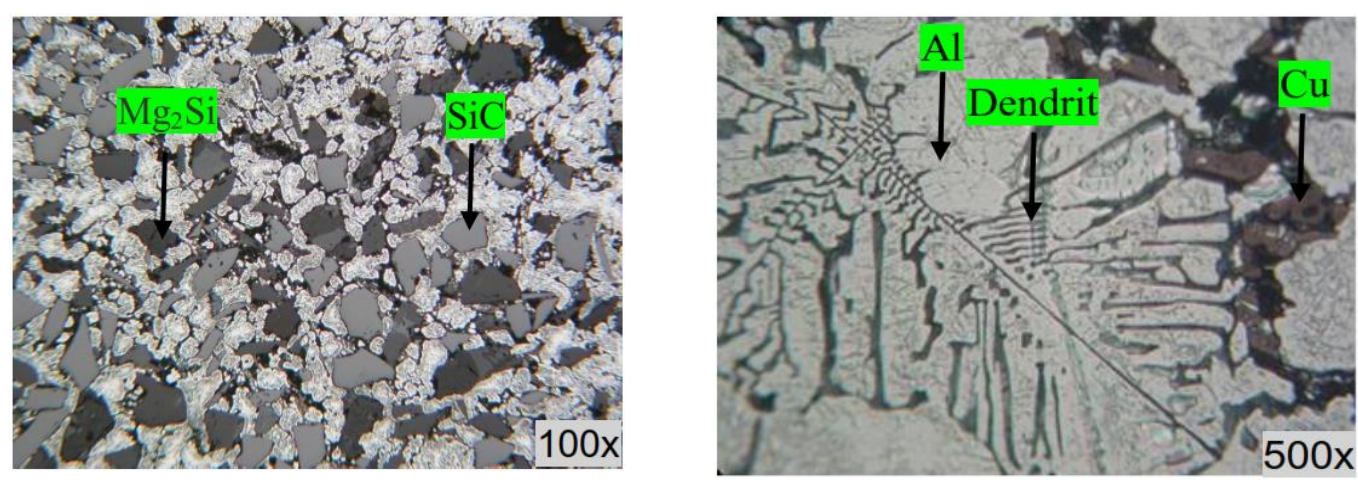

Gambar 4.9 Struktur mikro sampel kode 3000 material Al-SiC berupa dendrite aluminium (putih), SiC (abu abu butir besar), Silisium (sebagai batas butir dan telah menyebar pada butiran) dan $\mathrm{Cu}$ yang sudah mengalami perubahan warna.

(a) perbesaran 100x (b) perbesaran 500x. Etsa: Dix's keller reagent

Sehingga batas butir yang semakin rapat berdampak pada kekerasan pada material komposit $\mathrm{Al}-5 \% \mathrm{Cu}-12 \% \mathrm{Mg}-15 \% \mathrm{SiC}, \mathrm{SiC}$ meningkat dan sebaliknya. Pengaruh kecepatan putar juga berpengaruh terhadap wettability dari matrik, yaitu mampu membasahi partikel penguat yang berupa SiC. Dari strukutr mikro terlihat bahwa $\mathrm{SiC}$ dapat menyatu dengan matrik $\mathrm{AlCuMg}$ dikarenakan pengaruh wettability unsur Mg berpengaruh pada matrik. Dari gambar struktur mikro (1000) diketahui batas butirnya tidak rapat sehingga kekuatanya lebih rendah dibanding (2000), dan (3000).

Pada gambar juga terlihat struktur butir senyawa SiC pada putaran 2000 dan 3000 rpm sebarannya lebih merata dibandingkan putaran $1000 \mathrm{rpm}$, sehingga homogenitas material AMC dapat tercapai dengan baik. Hasil dari proses pengecoran Gambar 4.9 terlihat bahwa bentuk dari matriks tersebut merupakan fasa dendrit yang terbentuk karena kecepatan putar yang semakin ditingkatkan. Hal ini pun berpengaruh terhadap kekerasannya dimana kekerasan komposit hasil cor adalah 105.6 HB.

\section{KESIMPULAN}

Berdasarkan hasil pengujian dan analisa maka pada penelitian AMC dengan variasi temperatur waktu aging dapat di tarik kesimpulan sebagai berikut ini :

a. Kekerasan komposit bermatriks $\mathrm{Al}-5 \% \mathrm{Cu}-12 \% \mathrm{Mg}-15 \% \mathrm{SiC}$ akan meningkat seiring dengan peningkatan varian kecepatan putar. Peningkatan kecepatan 
putar berbanding terbalik dengan nilai keuletan material dimana semakin tinggi kecepatan putar maka kekuatannya menurun, karena terjadinya porositas berupa rongga halus pada permukaan partikel SiC seperti ditunjukkan pada gambar hasil struktur mikro. Porositas berupa rongga halus ini menjadikan ikatan antara permukaan partikel SiC dengan matrik aluminium menjadi berkurang dan menjadikan kekuatan tarik komposit menurun.

b. Proses stir casting menyebabkan perubahan bentuk struktur paduan Al$5 \% \mathrm{Cu} 12 \% \mathrm{Mg}-15 \% \mathrm{SiC}$ baik pada kecepatan putar $1000 \mathrm{Rpm}, 2000 \mathrm{Rpm}$ dan $3000 \mathrm{Rpm}$, dimana batas butir yang semakin rapat berdampak pada kekerasan pada material komposit $\mathrm{Al}-5 \% \mathrm{Cu}-12 \% \mathrm{Mg}-15 \% \mathrm{SiC}$, SiC meningkat dan sebaliknya. Pengaruh kecepatan putar juga berpengaruh terhadap wettability dari matrik, yaitu mampu membasahi partikel penguat yang berupa SiC. Struktur mikro AMC terlihat bahwa $\mathrm{SiC}$ dapat menyatu dengan matrik $\mathrm{AlCuMg}$ dikarenakan pengaruh wettability unsur $\mathrm{Mg}$ berpengaruh pada matrik. Dari gambar struktur mikro semakin besar kecepatan putar maka semakin merata pula sebaran $\mathrm{SiC}, \mathrm{Mg}$ dan Cu pada AMC.

\section{DAFTAR PUSTAKA}

[1] Smith, F. William, "Material Science and engineering" (second edition). NewYork: Mc Graw-Hillinc. 1995.

[2] Widi Aprianto, et. al., "Pemilihan bahan dan proses “ Universitas Jenderal Achmad Yani., Bandung, 2014.

[3] Suyanto, et al., Sulardjaka., Sri Nugroho, "Pengaruh Komposisi Mg dan SiC Terhadap Sifat Kekerasan Komposit AlSi-SiC yang dibuat dengan Proses Semi Solid Stircasting” Universitas Diponogoro, 2017.

[4] Anne Zulfa, et. al., "Proses Penuaan (Aging) pada Paduan Aluminium AA 333 Hasil Proses Sand Casting”. Universitas Indonesia, Jakarta. 2010.

[5] Juriah Mulyanti, "Pengaruh Temperatur Aging Terhadap Karakteristik Material Komposit Logam Al-SiC Hasil Stir casting”, Universitas Janabadra, 2011.

[6] Supriatna, "Pengaruh Perlakuan Panas Dan Penuaan Terhadap Sifat Mekanis Pada Material Komposit Matrik Al-4,5\%Cu-4\%Mg-10\%SiC(P)", Universitas Gunadarma. 2017. 
[7] Fuad Abdillah., "Perlakuan Panas Paduan Al-Si pada prototype piston berbasis material piston bekas". Universitas Diponegoro : Semarang. 2010.

[8] B Bakri, S Chandrabakty, 'Efek Waktu Perlakuan Panas Temper Terhadap Kekuatan Tarik dan Ketangguhan Impak Baja Komersial” SMARTek 4 (2), 2012

[9] Pengaruh Variasi Temperatur Tuang Terhadap Ketangguhan Impak dan Struktur Mikro pada Pengecoran Alumunium, Simetris Jurnal Teknik Mesin, Elektro dan Ilmu Komputer 8 (1) Hal. 219-224, 2017.

[10] Amir Arifin, et. al., "Pengaruh Parameter Stir Casting Terhadap Sifat Mekanik Alumunium Matrx Composite (AMC)" Flywheel, Jurnal Teknik Mesin Untirta Volume III Nomor 1 Hal. 21-31, 2017.

[11]Iman Saefuloh, et. al., "Studi Karakteristik Sifat Mekanik Alumunium Matrix Composite (AMC) Paduan AL, 5\% Cu, 12\% Mg, 15\% SiC Hasil Proses Casting dengan Variasi Temperatur Pengadukan, Jurnal Teknika Untirta Edisi 14 No. 2 Hal. $151-164,2018$.

[12] Iman Saefuloh, et. al., "Studi mechanical properties dan struktur mikro hasil variasi temperatur dan waktu aging pada alumunium matrix composite (AMC) hasil proses stir casting dengan kandungan matrix Berlebih" Jurnal Mesin Nusantara Vol. 1 No. 2 Hal. 60-68, 2018. 